\title{
Effects of selected medicinal plant extracts on mitochondrial function
}

\author{
ABENAA SERWAA ACHAMPONG, AUGUSTINE OCLOO", REGINA APPIAH-OPONG \\ Department of Biochemistry, Cell and Molecular Biology, University of Ghana. Legon, Accra, Ghana. ^email. aocloo@ug.edu.gh
}

Manuscript received: 9 August 2018. Revision accepted: 10 December 2018.

\begin{abstract}
Achampong AS, Ocloo A, Appiah-Opong R. 2019. Effects of selected medicinal plant extracts on mitochondrial function. Biofarmasi J Nat Prod Biochem 17: 1-13. Mitochondria are organelles that produce approximately $90 \%$ of the energy required by the eukaryotic cell through oxidative phosphorylation. Mitochondria also play vital roles in other metabolic processes in the cell. Mitochondria have unique features that make them sensitive to some xenobiotics. Thus, they serve as primary or secondary targets for these xenobiotics. Medicinal plants are the source of phytochemicals that also have the potential to regulate mitochondrial function. Therefore, it is necessary to study the effects of these medicinal plants, especially those in Ghana, on mitochondrial function. The objectives of this study were to determine the effects of Taraxacum officinale, Morinda citrifolia, and Millettia thonningii on mitochondrial function. The extracts' antioxidant properties, phenolic content, and phytochemicals were determined. We determined the effect of the extract on cell viability and mitochondrial respiratory chain activity. All extracts significantly stimulated basal respiration and also caused an increase in complex IV respiration. The extracts exhibit considerable antioxidant activity, and all contain phytochemicals that have been shown to have antioxidant properties. M. thonningii partially blocked the effects of rotenone, while Noni juice partially blocked the effects of antimycin A. The extract, however, had a weak cytotoxic effect on Jurkat leukemia cells and MCF7 breast cancer cells.
\end{abstract}

Keywords: Mitochondria, Millettia thonningii, Morinda citrifolia, Taraxacum officinale

\section{INTRODUCTION}

Mitochondria are essential organelles present in the eukaryotic cell, which produce about $90 \%$ of the energy needed by the cell in the form of adenosine triphosphate (ATP) through a process known as oxidative phosphorylation (Nadanaciva et al. 2007). Mitochondria also play essential roles in fatty acid $\beta$-oxidation, apoptosis, heme synthesis, and calcium metabolism (Scatena et al., 2007).

Mitochondria also have unique properties that enable them to carry out their functions and make them sensitive to chemical compounds. For example, they have a double membrane consisting of the outer and the inner membrane. The cholesterol-rich outer membrane describes all the organelles, while the cardiolipin-rich inner membrane encloses the matrix. Moreover, mitochondria are the only organelles in animal cells containing their DNA and have a basic interior (Wallace and Starkov 2000).

These unique properties serve as the primary or secondary targets for drugs and other xenobiotics (Wallace and Starkov 2000). Consequently, several drugs produce pharmacological effects through their interaction with the mitochondria. For instance, the immunosuppressant, Cyclosporin A, is known to prevent the induction of the mitochondria permeability transition pore (MPTP) and hence provide protection against ischemic-reperfusion injuries (Smith et al. 2012). Idebenone is another drug that acts as an antioxidant. The drug increases the complex I activity of the electron transport chain (ETC) and protects against neurodegeneration and cardiomyopathy (Smith et al., 2012). Methylene blue is reported to increase complex
IV activity in Alzheimer's models (Smith et al., 2012).

However, some compounds exhibit their toxic effects by interfering with mitochondrial function. Widely used as a drug in treating epilepsy and other seizures, Valproic acid, is a substrate for the fatty acid $\beta$-oxidation pathway, primarily in the mitochondrion. The toxicity of valproate is considered primarily due to its interference with mitochondrial $\beta$-oxidation (Silva et al. 2008). Other antiretroviral drugs, such as zidovudine, have also induced mitochondrial toxicity (Lewis et al., 2003). Zidovudine inhibits the function of DNA polymerase polymerase- $\gamma$ (DNA pol-polymer) - the enzyme that replicates mtDNA. This pol- $\gamma$ inhibition leads to depletion of mtDNA and thus to mitochondrial dysfunction (Lewis and Dalakas 1995). Well-characterized drugs are associated with side effects where oxidative stress may contribute to nonsteroidal antiinflammatory drugs (NSAIDs), antipsychotics, and analgesics (Deavall et al., 2012).

The toxic effect produced by some of these drugs on the mitochondria subsequently leads to failure of energy generation and mitochondrial dysfunction (Wallace and Starkov 2000). Impaired mitochondrial function induces uncoupling oxidative phosphorylation, ATP depletion, and excessive reactive oxygen species (ROS) production. Mitochondrial dysfunction has been linked with a range of pathological conditions, including diabetes, obesity, Parkinson's disease, Alzheimer's disease, lactic acidosis, cancer, and retinopathy (Scatena et al., 2007; Wallace, 2013). Therefore, although mitochondria serve as critical primary targets for drugs, some medications lead to toxicity. Thus, in drug development, including the development of medicinal plant products, it is essential to 
study the compound's effect on mitochondrial function to predict and prevent the severe side effects of the mixtures and the herbal preparations. Gohil et al. (2010) have screened an extensive array of drugs already in clinical use and classified several interfering with mitochondrial function.

Medicinal plant extracts contain many phytochemicals, including alkaloids, flavonoids, polyphenols, and tannins. These phytochemicals can interfere with mitochondrial function, just like synthetic compounds and drugs (Wallace and Starkov 2000; Forbes-Hernandez et al. 2014). Phyllanthus urinaria has been found to inhibit complex I and complex II of the ETC and significantly induces a decline in mitochondrial respiration (Huang et al., 2014). Dichloromethane extract from the seeds of Millettia thonningii has been shown to inhibit complex I activity, and this inhibition is believed to be responsible for its molluscicidal and schistosomicidal actions (Lyddiard and Whitfield 2001). Similarly, the ethanolic extract of Paulinia pinnata has been reported to inhibit the activity of complex II, which may explain the reported toxicity in fish (Ocloo et al., 2015). Although there has been some research on several medicinal plants on their effects on mitochondria, there is currently little information on therapeutic plant yields in sub-Saharan Africa on mitochondrial function.

The objectives of this research were (i) to determine the effects of aqueous leaf extracts of $T$. officinale, $M$. citrifolia and $M$. thonningii, and $M$. citrifolia fruit juice (Noni juice) on the mitochondria complexes I-IV activity in situ in permeabilized cardiac fibers; (ii) to assess the effects of the aqueous leaf extracts of $T$. officinale, $M$. citrifolia and $M$. thonningii, and Noni juice on mitochondrial function in leukemia (Jurkat) and breast cancer (MCF7) cell lines using the MTT assay; (iii) to determine the antioxidant activities, phenolic content, and phytochemistry of the leaf extracts of $T$. officinale, $M$. citrifolia, M. thonningii, and Noni juice.

\section{MATERIALS AND METHODS}

\section{Chemicals and reagents}

All chemicals were purchased from Sigma-Aldrich (Bournemouth, U.K.) except $\mathrm{MgCl}_{2} \cdot 6 \mathrm{H}_{2} \mathrm{O}$ (Barcelona, Spain), sucrose (Karlsruhe, Germany), imidazole (Belgium), and $\mathrm{KH}_{2} \mathrm{PO}_{4}$ (Frankfurt, Germany).

\section{Plant materials}

The leaves were harvested at different locations. $T$. officinale Weber leaves were harvested at Adabraka, Accra, Ghana, while M. citrifolia leaves were harvested at Ayikuma, Greater Accra Region of Ghana. M. thonningii (Schum. \& Thonn) Baker leaves were harvested near Botany, University of Ghana, Ghana. Noni juice was purchased from the Royal Noni Factory at Dzorwulu, Accra, Ghana. Prosper Avekor confirmed the identity of each plant specimen at the Department of Botany, University of Ghana, Legon. The voucher specimen were T. officinale (GC45929), M. citrifolia (ASMC1014), and

\section{M. thonningii (CSRPM/406).}

\section{Preparation of plant materials}

The leaves of three medicinal plants, T. officinale, $M$. citrifolia, and $M$. thonningii, were air-dried for three weeks and subsequently pulverized with a blender. To obtain the aqueous extract, the pulverized samples were dissolved in distilled water $(500 \mathrm{~mL})$ to $50 \mathrm{~g}$ of the powdered sample (10\% of a mixture prepared). The resulting mixture was heated at $80^{\circ} \mathrm{C}$ for 1 hour, cooled to room temperature, and centrifuged at $4500 \mathrm{x} \mathrm{g}$ for 20 minutes. The supernatant was removed by decantation. The pellet was re-suspended in $500 \mathrm{~mL}$ distilled water. The supernatant obtained was decanted, collected, and mixed with the previous one. The heating and centrifugation of the extracts were repeated. The leaf extracts and Noni juice were frozen-dried in a Supermodulyo freeze-dryer (Thermo Electron Corporation, USA).

\section{Analysis of the effect of the extracts on mitochondrial complexes}

Preparation of tissues for permeabilization

Male ICR mice (3-5 months) with an average weight of $28.75 \mathrm{~g}$ were obtained from the Centre for Plant Medicine Research (CPMR), Akuapem-Mampong, Ghana. The mice were acclimatized in the laboratory for 24 hours and then sacrificed.

The myocardial tissues were isolated using scissors and forceps, then placed in ice-cold isolation buffer $(7.23 \mathrm{mM}$ $\mathrm{K}_{2}$ EGTA, $2.77 \mathrm{mM} \mathrm{CaK}{ }_{2}$ EGTA, $5.77 \mathrm{mM} \mathrm{Na} 2 \mathrm{ATP}, 20$ $\mathrm{mM}$ taurine, $6.56 \mathrm{mM} \mathrm{MgCl}_{2} .6 \mathrm{H}_{2} \mathrm{O}, \quad 15 \mathrm{mM}$ $\mathrm{Na}_{2}$ Phosphocreatine, $20 \mathrm{mM}$ imidazole, $0.5 \mathrm{mM}$ dithiothreitol, $50 \mathrm{mM}$ MES). The samples were then transferred to a plastic petri dish containing a small amount of the ice-cold isolation buffer. Fat and connective tissues were removed. Next, the myocardial tissue was dissected into muscle strips under a dissecting microscope. Next, these strips were further dissected into thin muscle fibers.

\section{Permeabilization of mouse cardiac tissues}

The fiber bundles were permeabilized by transferring them into a vial containing isolation buffer $(2 \mathrm{~mL})$ and 50 $\mu \mathrm{g} / \mathrm{mL}$ of saponin and mixed gently on a rocker-shaker at $4^{\circ} \mathrm{C}$ for 20 minutes. Next, the permeabilized fibers were washed by transferring them into another vial containing the respiration medium $(0.5 \mathrm{mM}$ EGTA, three $\mathrm{mM}$

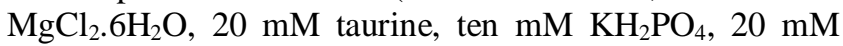
HEPES, $110 \mathrm{mM}$ sucrose, one $\mathrm{g} / \mathrm{l}$ fatty acid-free BSA) and mixed gently at $4^{\circ} \mathrm{C}$ for 5 minutes to wash out the saponin (Kuznetsov et al. 2008). This step was repeated three more times.

\section{Measurement of oxygen consumption}

Oxygen consumption rates were monitored using a Clark-type oxygen electrode (Strathkelvin Instruments Limited, Scotland) in a sealed chamber at $37^{\circ} \mathrm{C}$. The Clarktype oxygen electrode consists of a platinum or gold cathode and silver/silver chloride anode separated by a potassium chloride electrolyte solution. An oxygenpermeable membrane separates the two-half cells from the 
experimental assay media. When a voltage is applied across the two half-cells, oxygen passes through the membrane and is reduced at the cathode to the hydroxyl

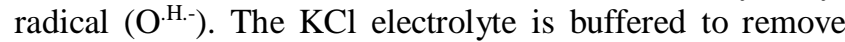

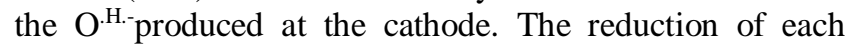
oxygen molecule is accompanied by 4 electrons of current flow in the circuit.

The signal generated by the electrode is linear concerning the molecular oxygen flux to the cathode. This oxygen flux is also proportional to the partial pressure of oxygen $\left(\mathrm{PO}_{2}\right)$ of the respiratory medium, membrane permeability, temperature, and cathode surface area (Strathkelvin Instruments Ltd. 2012). During respiration testing, the output signal from the oxygen meter is digitally collected every second by the Strathkelvin 782 system software. The data files are converted to absolute values based on the oxygen content of $210 \mathrm{~mol} \mathrm{O}_{2}$ and the amount of mitochondrial protein used.

For oxygen consumption measurements, Permeabilized fibers $(2.5-4 \mathrm{mg})$ were added to a continuously stirred respiration medium $(500 \mu \mathrm{L})$. The fibers were incubated with the extracts $(2 \mu \mathrm{L})$ at a $10 \mathrm{mg} / \mathrm{mL}$ concentration for 2 minutes. Functional analysis of the respiratory chain enzyme complexes was performed using specific substrates and inhibitors in a substrate-inhibitor titration (Kuznetsov et al. 2008).

In this titration, $1.25 \mu \mathrm{L}$ of $0.8 \mathrm{M}$ malate and $2.5 \mu \mathrm{L}$ of $2 \mathrm{M}$ glutamate (complex I substrates) were first added to the polygraph chambers to measure complex I respiration. This step was continued by adding $510.5 \mathrm{M}$ ADP to obtain maximum mitochondrial respiration. Inhibition of complex I was achieved by adding $0.2510 .01 \mathrm{M}$ rotenone. Next, 51 of $1 \mathrm{M}$ succinate was added to stimulate respiration of complex II. Next, an aliquot of $0.25 \mu \mathrm{L}$ of $0.02 \mathrm{M}$ antimycin A was added to inhibit complex III respiration. This was followed by measuring the complex IV respiration by adding $0.2 \mathrm{M}$ TMPD $\left(\mathrm{N}, \mathrm{N}, \mathrm{N}^{\prime}, \mathrm{N}^{\prime}-\right.$ tetramethyl-p-phenylenediaminedihydrochloride) $(1.25 \mu \mathrm{L})$ and $0.8 \mathrm{M}$ ascorbate (artificial substrates of complex IV) $(1.25 \mu \mathrm{L})$. Finally, the efficacy of the preparation was evaluated by confirming mitochondrial integrity through the addition of cytochrome $\mathrm{C}(1.25 \mu \mathrm{L} ; 4 \mathrm{mM})$.

\section{Determination of the effects of the extracts on cell viability}

The cytotoxic effect of the extracts was evaluated using a tetrazolium-based colorimetric [3-(4, 5-dimethyl thiazol2-yl)-2, 5-diphenyl tetrazolium bromide] (MTT) assay based on Ayisi (2011). The cell lines used in this study were the Jurkat leukemia and MCF7 breast cancer cell lines. The MCF7 cells were maintained in DMEM-10\% FBS, while the Jurkat cells were maintained in RPM I 1640 supplemented with $10 \%$ FBS. The cells were incubated at $37^{\circ} \mathrm{C}$ in the presence of $5 \%$ C.O. They were then seeded ( 1 d $\times 10^{5}$ cells $/ \mathrm{mL}$ ) into 96 -well plates pre-treated with varying concentrations $(0-1000 \mu \mathrm{g} / \mathrm{mL})$ of $\mathrm{t} h$ e crude extracts. Curcumin was used as the positive control. The experiment was carried out in triplicate.

After incubating cells with the extract for 72 hours, 201 of $2.5 \mathrm{mg} / \mathrm{mL}$ MTT solution was added to each well, and incubation lasted for 4 hours. The reaction was then stopped with acidified isopropanol (150 1), after which the plates were incubated overnight in the dark. Optical density was read using a Tecan Infinite M200 (Austria) plate reader at a wavelength of $570 \mathrm{~nm}$. Cytotoxicity was determined by the concentration of the extracts, which inhibit $50 \%$ cellular proliferation $\left(\mathrm{IC}_{50}\right)$. In addition, percent cell survival was evaluated, and IC50 values were determined.

\section{Determination of antioxidant activities of the extracts}

The free radical scavenging activities of the samples were evaluated using the 2,2-diphenyl-1-picrylhydrazyl (DPPH) method with slight modification (Blois 1958). Each extract $(10 \mathrm{mg} / \mathrm{mL})$ was prepared by dissolving the dry extract in distilled water. An amount of $10 \mathrm{mM}$ butylated hydroxytoluene (BHT) was applied as the positive control. Extracts were prepared at various concentrations ranging from $0-5 \mathrm{mg} / \mathrm{mL}$. The reaction mixture was $100 \mu \mathrm{L}$ of plant extract or BHT and $100 \mu \mathrm{L}$ of $0.05 \mathrm{mM}$ DPPH in 96-well plates. Triplicate experiments were performed. The samples were incubated in the dark for 20 minutes (RT). The absorbance was read at $517 \mathrm{~nm}$ using a microplate reader (Tecan Infinite M200, Austria).

The free radical scavenging capacity of each sample was calculated as the percent DPPH radical scavenging effect using the below formula:

\section{$\%$ DPPH Scavenging effect $=\left[\left(\mathrm{A}_{0}-\mathrm{A}_{1}\right) / \mathrm{A}_{0}\right] \times 100$,}

Where: $A_{0}$ is the absorbance of the blank solution, and $A_{1}$ is the absorbance of the extract. The $E_{50}$ (extract concentration to produce $50 \%$ reduction of $\mathrm{DPPH}$ ) values were calculated from a plot of the \% DPPH scavenging effect versus log concentration of extract; the lower the $\mathrm{EC}_{50}$ value, the higher the antioxidant activity and vice versa.

\section{Determination of total phenolic content of extracts}

The total phenolic content of the sample was calculated based on the Folin-Ciocalteau assay (Marinova et al. 2005) with slight modification. TFolin-Ciocalteu reagent is a mixture of tungstate and molybdate (Jadhav et al., 2012). The polyphenols in plant extracts react with the FolinCiocalteu reagent to create a blue complex (a phosphotungsticphosphomolybdenum complex) quantified by visible light spectrophotometry (Schofield et al. 2001). The blue color produced has maximum absorption in the region of $750 \mathrm{~nm}$ and is proportional to the total amount of phenolic compounds present.

$5 \mathrm{mg} / \mathrm{mL}$ of each extract was prepared to determine the total phenolic content. The aliquot of extract $(10 \mu \mathrm{L})$ was added to $790 \mu \mathrm{L}$ of distilled water in each well. To this solution, Folin-Ciocalteau reagent $(50 \mu \mathrm{L})$ was added. The resulting solution was thoroughly mixed and incubated in the dark for 8 minutes. Next, the solution was added with $150 \mu \mathrm{L}$ of $7 \% \mathrm{Na}_{2} \mathrm{CO}_{3}$ and further incubation for 2 hours in the dark at room temperature. The experiment was performed in duplicates. Absorbance was read at a wavelength of $750 \mathrm{~nm}$ using a microplate reader (Tecan Infinite M200, Austria). Meanwhile, Gallic acid was used as the standard phenolic compound to make a calibration curve (Figure 1). 


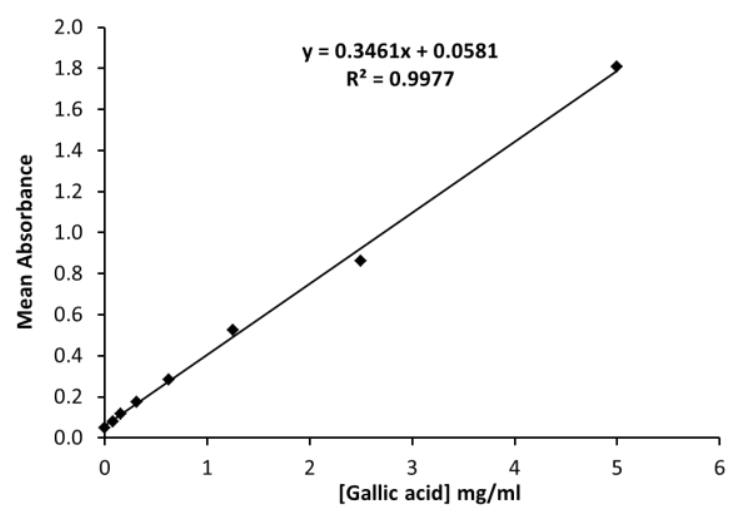

Figure 1. Calibration curve for gallic acid

\section{Phytochemical analysis}

The crude extracts and Noni juice were assayed for the presence of six phytochemicals: alkaloids, flavonoids, cardiac glycosides, saponins, tannins, and terpenoids. As described elsewhere, the alkaloids were tested (Sofowora 1993; Evans 2002) with slight modification. Finally, tests for the other phytochemicals were carried out as described (Mir et al., 2013).

\section{Determination of the presence of alkaloids in the extracts}

$0.1 \mathrm{~g}$ of each crude extract was weighed into $5 \mathrm{~mL}$ of 2 $\mathrm{M}$ hydrochloric acid $(\mathrm{HCl})$ solution. The mixed solution was stirred, warmed, and filtered. The filtrate from each extract was then divided into three portions. Dragendorff's reagent was added to one part of each test solution, while Mayer's reagent was added to another amount. Wagner's reagent was added to the third portion of the test solutions. The presence of a yellowish or reddish-brown precipitate indicated the presence of alkaloids.

\section{Determination of the presence of glycosides}

An aliquot of aqueous extract $(5 \mathrm{~mL})$ containing $0.1 \mathrm{~g}$ of extract was mixed with $2 \mathrm{~mL}$ of glacial acetic acid $\left(\mathrm{CH}_{3} \mathrm{COOH}\right)$ having one drop of ferric chloride $\left(\mathrm{FeCl}_{3}\right)$. Concentrated sulfuric acid $\left(\mathrm{H}_{2} \mathrm{SO}_{4}\right)(1 \mathrm{~mL})$ was added carefully to the above mixture so that concentrated $\mathrm{H}_{2} \mathrm{SO}_{4}$ was at the bottom of the mixture. The appearance of a brown ring indicates the presence of glycoside constituents.

\section{Determination of the presence of flavonoids}

An amount of $0.1 \mathrm{~g}$ of each crude extract was added to $5 \mathrm{~mL}$ of $80 \%(\mathrm{v} / \mathrm{v})$ ethanol. The resulting solution is filtered and divided into two parts. In one part of the filtrate, a magnesium lathe is added. This step was followed by adding $0.5 \mathrm{~mL}$ of concentrated $\mathrm{HCl}$, and the solution was monitored for 10 minutes to observe color changes. Next, concentrated $\mathrm{HCl}(5 \mathrm{~mL})$ was added to another portion, and the solution was warmed for 5 minutes. Observation of light pink color is an indication of the presence of flavonoids.

\section{Determination of the presence of saponins}

Each extract of as much as $0.5 \mathrm{~g}$ was boiled together for 30 seconds with $5 \mathrm{~mL}$ of distilled water and then filtered.
The filtrate $(2.5 \mathrm{~mL})$ was then mixed with $1.25 \mathrm{~mL}$ of distilled water and shaken vigorously to obtain a stable and persistent froth. Three drops of olive oil are added to the foam. The formation of an emulsion indicates the presence of saponins.

\section{Determination of the presence of tannins}

To detect the presence of tannins, $0.25 \mathrm{~g}$ of extract was boiled in $10 \mathrm{~mL}$ of distilled water for 30 seconds and then filtered. This is followed by adding 3 drops of $0.2 \% \mathrm{FeCl}_{3}$ to filtrate. The observation of a brownish-green or a blueblack coloration indicated the presence of tannins.

\section{Determination of the presence of terpenoids}

Aqueous extract $(5 \mathrm{~mL})$ containing $0.1 \mathrm{~g}$ of the extract was mixed with $2 \mathrm{~mL}$ of chloroform $\left(\mathrm{CHCl}_{3}\right) .3 \mathrm{~mL}$ of concentrated $\mathrm{H}_{2} \mathrm{SO}_{4}$ was carefully added to the mixture to form a layer of the aqueous extracts. An interface indicated the presence of terpenoids with reddish-brown coloration.

\section{Data analysis}

The data for the antioxidant, cell viability, and mitochondrial respiration measurements were analyzed as described below:

The $\mathrm{EC}_{50}$ values obtained in the DPPH assay were calculated from plots of\%DPPH scavenging effects versus log extract concentrations using GraphPad Prism version 5.0 (GraphPad Prism Software Inc., San Diego, CA). The DPPH radical scavenging effect was calculated using the formula:

$\%$ DPPH Scavenging effect $=\left[\left(\mathrm{A}_{0}-\mathrm{A}_{1}\right) / \mathrm{A}_{0}\right] \times 100$,

Where: $A_{0}$ represents the absorbance of the blank and $A_{1}$ is the absorbance of the extract

Nilai IC50 yang diperoleh dalam uji MTT ditentukan dari plot persen viabilitas sel versus konsentrasi ekstrak menggunakan Microsoft Excel. The percent cell viability was calculated using the formula:

$$
\% \text { Cell viability }=\left(\mathrm{A}_{1} / \mathrm{A}_{0}\right) \times 100
$$

Where: $A_{0}$ is the absorbance of the blank and $A_{1}$ is the absorbance of the extract

The respiration test was analyzed using the Strathkelvin 782 system, which converts the respiratory rate to an absolute value in Microsoft Excel. Each plant extract was evaluated five times, and the values were recorded as mean \pm SEM. Comparisons between means were made, and significance was assessed by one-factor analysis of variance using Microsoft Excel. The probability value of $P$ $<0.05$ was used as a criterion for a significant difference.

The respiratory control ratio (RCR) was calculated as state 3/state 2 to measure mitochondrial coupling. State 3 respiration was stimulated by adding $0.5 \mathrm{M}$ ADP, while State 2 respiration was produced by adding $0.08 \mathrm{M}$ malate and $2 \mathrm{M}$ glutamate. Leakage respiration was also determined from $\mathrm{G}+\mathrm{M}$-stimulated respiration (second 
respiratory status) in the absence of ADP. Leaky respiration measures the leakage of protons across the inner mitochondrial membrane.

\section{RESULTS AND DISCUSSION}

\section{Effects of the selected plant extracts on mitochondrial function in saponin-permeabilized cardiac fibers}

The effects of the selected extracts on mitochondrial respiratory chain activity are displayed in Figure 2. The first pair of rods showed incubation of permeabilized fibers only in the presence of solvents or extracts. This breathing proved minimal. Complex I respiration is stimulated by adding glutamate and malate $(\mathrm{G}+\mathrm{M})$ and is represented by the second pair. The third pair showed the activation of oxidative phosphorylation with the addition of ADP. The fourth pair shows inhibition of complex I by rotenone, a known complex I inhibitor. Complex II respiration is stimulated by the accumulation of succinate and is indicated by the fifth pair. The sixth pair represents complex III inhibition by antimycin A, a known complex III inhibitor. The seventh pair represents the addition of ascorbate and N,N,N',N-tetramethyl-p-phenylenediamine (TMPD) to stimulate respiration via complex IV. Ascorbate and TMPD are artificial electron donors to complex IV. The last pair of bars represents cytochrome $\mathrm{C}$, a test for the intactness of the outer mitochondrial membrane.

\section{Effects of $T$. officinale on mitochondrial respiratory chain activity}

In the presence of the $T$. officinale extract alone, there was significant minimal respiration, while no respiration was observed in the presence of the control/solvent alone (Figure 2). Subsequent addition of substrates and inhibitors resulted in insignificant changes. G+M stimulated respiration appeared unaffected by the $\mathrm{T}$. officinale extract compared to the solvent. The extract did not significantly decrease ADP-stimulated respiration, rotenone-inhibited respiration, succinate-stimulated respiration, and antimycin A-inhibited respiration compared to the solvent. However, the ascorbate+TMPD-stimulated respiration increased nonsignificantly in the presence of the $T$. officinale extract compared to the solvent. The addition of cytochrome $\mathrm{C}$ appeared to elicit a non-significant increase in respiration rate in the presence of the T. officinale extract compared to the solvent.

\section{Effects of Morinda citrifolia on mitochondrial respiratory chain activity}

In the presence of the solvent alone, no respiration was observed. However, when the Morinda citrifolia was independently added, significant minimal respiration was observed (Figure 3). The M. citrifolia extract also caused a substantial increase in the complex IV respiration compared to the solvent. On the other hand, in the presence of this extract, a non-significant decrease in respiration was observed with the addition of G+M, ADP, succinate, and antimycin.
Compared with the solvent, rotenone-inhibited respiration did not appear to be affected in the presence of $M$. citrifolia extract. The addition of cytochrome $\mathrm{C}$ seemed to cause an insignificant increase in respiration in the presence of $M$. citrifolia to extract compared to the solvent.

\section{Effects of noni juice on mitochondrial respiratory chain activity}

There was significant minimal respiration observed in the presence of the Noni juice extract alone (Figure 4). Subsequent addition of substrates and inhibitors resulted in insignificant changes. Noni juice extract did not significantly increase antimycin A-inhibited respiration and ascorbate + TMPD-stimulated respiration. However, Noni juice extract did not significantly decrease G+M stimulated respiration, ADP stimulated respiration, rotenone-inhibited respiration, and succinate stimulated respiration insolvent. The addition of cytochrome $\mathrm{C}$ seems to cause an insignificant increase in respiration compared to the solvent.

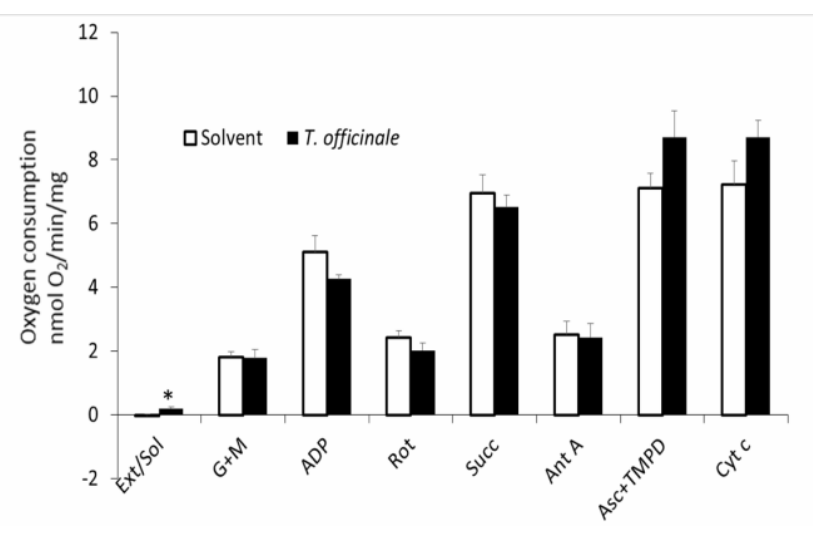

Figure 2. Effects of T. officinale and solvent on respiration rates; Values are means \pm SEM $(n=5): 2 \mu \mathrm{L}$ of solvent, $2 \mu \mathrm{L}$ of 10 $\mathrm{mg} / \mathrm{mL}$ of extract; Black bars represent respiration rates in the presence of the extracts (ext); White bars indicate respiration rates in the presence of the solvent (sol) *-Values significantly different from control $(\mathrm{p}<0.05)$.

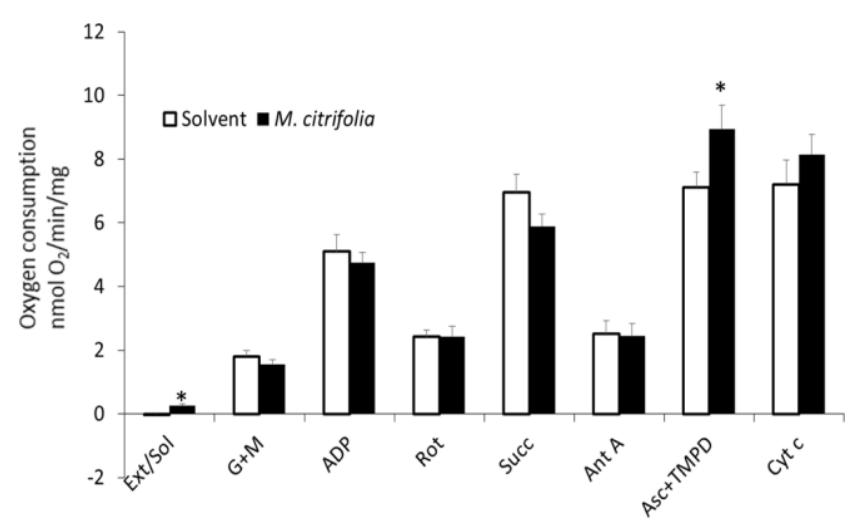

Figure 3. Effects of $M$. citrifolia and solvent on respiration rates; Values are mean \pm SEM $(n=5): 2 \mu \mathrm{L}$ of solvent, $2 \mu \mathrm{L}$ of 10 $\mathrm{mg} / \mathrm{mL}$ of extract; Black bars indicate respiration rates in the presence of the extracts (ext); White bars indicate respiration rates in the presence of the solvent (sol) *-Values significantly different from control $(\mathrm{p}<0.05)$. 


\section{Effects of $M$. thonningii on mitochondrial respiratory chain activity}

Similar to the trend observed with the other extracts, the $M$. thonningii extract alone appeared to have stimulated significantly minimal respiration compared to the solvent (Figure 5). Non-significant changes were observed with the addition of the substrates and inhibitors. G+M stimulated the M. thonningii extract but did not alter respiration compared to the solvent. $M$. thonningii extract did not significantly increase ADP-stimulated respiration, rotenone-inhibited respiration, and ascorbate+TMPD stimulated respiration. However, succinate-stimulated respiration and antimycin A-inhibited respiration did not appear to be significantly decreased in the presence of $M$. thonningii extract compared to the solvent. The addition of cytochrome $\mathrm{C}$ caused an insignificant increase in respiration in the presence of $M$. thonningii extract compared to the solvent.

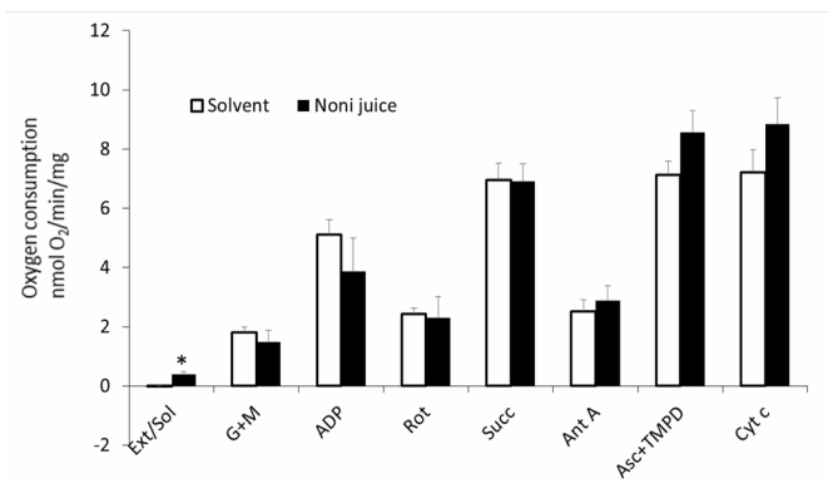

Figure 4. Effects of Noni juice and solvent on respiration rates; Values are mean \pm SEM $(n=5): 2 \mu \mathrm{L}$ of solvent, $2 \mu \mathrm{L}$ of 10 $\mathrm{mg} / \mathrm{mL}$ of extract; Black bars indicate respiration rates in the presence of the extracts (ext); White bars denote respiration rates in the presence of the solvent (sol) *-Values significantly different from control $(\mathrm{p}<0.05)$

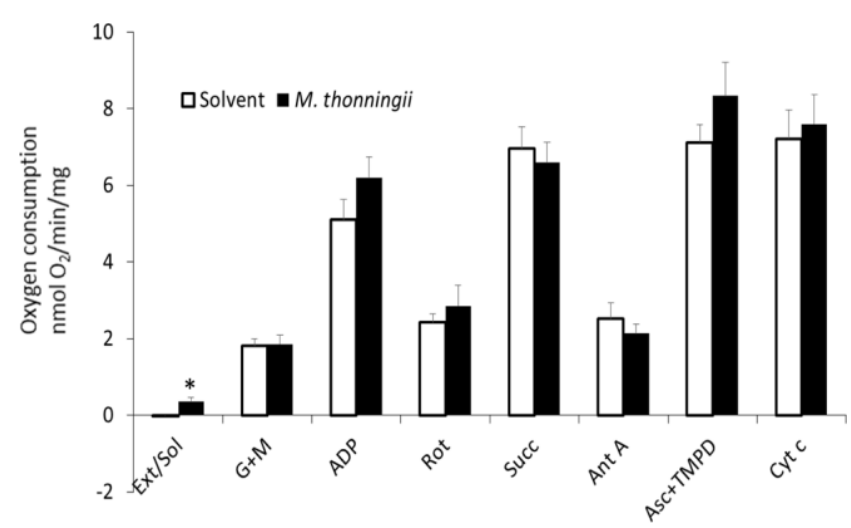

Figure 5. Effects of $M$. thonningii and solvent on respiration rates; Values are mean + SEM, $(n=5): 2 \mu \mathrm{L}$ of solvent, $2 \mu \mathrm{L}$ of 10 $\mathrm{mg} / \mathrm{mL}$ of extract; Black bars showed respiration rates in the presence of the extracts (ext); White bars indicate respiration rates in the presence of the solvent (sol); *-Values significantly different from control $(\mathrm{p}<0.05)$
Effects of the plant extract on respiratory control ratio (RCR) and leak respiration.

The RCR values obtained for the extracts are indicated in Table 1. Taraxacum officinale, Millettia thonningii, and Morinda citrifolia increased RCR values more than the solvent and seemed to have non-significantly increased coupling. However, the RCR in the presence of the Noni juice was lower than the solvent, indicating that the Noni juice appeared to have non-significantly decreased coupling.

Figure 6 shows a graph of the effects of the extracts on the leak respiration. The leak of respiration was not observed in all tested samples. The M. thonningii and T. officinale extracts appeared to have caused slightly lower leak respiration than the solvent. The $\mathrm{M}$. citrifolia and Noni juice extracts appeared to have caused much lower leak respiration than the solvent.

\section{Effects of plant extracts on cell viability}

Curcumin, a positive control, had $\mathrm{IC}_{50}$ values of $11.4 \mathrm{M}$ and 74.24 M (Fig. 7A) in Jurkat leukemia cells and MCF7 breast cancer cells, respectively. However, the $\mathrm{IC}_{50}$ values of the extracts obtained in the Jurkat leukemia cells were more significant than $100 \mu \mathrm{g} / \mathrm{mL}$, although dose-dependent responses were observed (Figure 7). No $\mathrm{IC}_{50}$ values were obtained for Noni juice in Jurkat leukemia cells. At the highest concentration tested, noni juice could inhibit the growth of Jurkat cells by about $40 \%$. In addition, no $\mathrm{IC}_{50}$ value was obtained for any of the extracts in MCF7 breast cancer cells, and a flat curve was observed (Fig. 8). The $\mathrm{IC}_{50}$ values have been summarized in table 2 .

Table 1. Effects of plant extracts on mitochondrial respiratory control ratio (RCR)

\begin{tabular}{lc}
\hline \multicolumn{1}{c}{ Extracts } & RCR \\
\hline Solvent & $2.82 \pm 0.16$ \\
T. officinale & $3.23 \pm 0.80$ \\
M. citrifolia & $3.15 \pm 0.37$ \\
Noni juice & $2.49 \pm 0.70$ \\
M. thonningii & $3.52 \pm 0.83$ \\
\hline
\end{tabular}

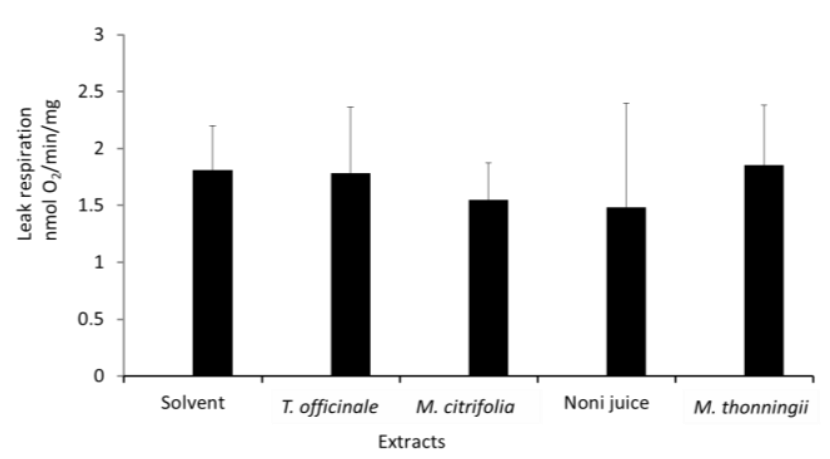

Figure 6. Effects of the extracts on leak respiration (proton leak across the inner membrane) 


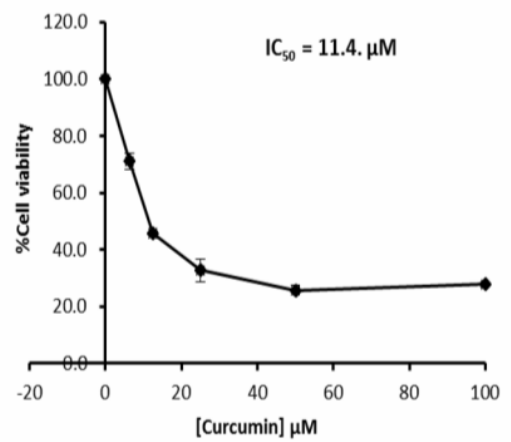

$\mathbf{A}$

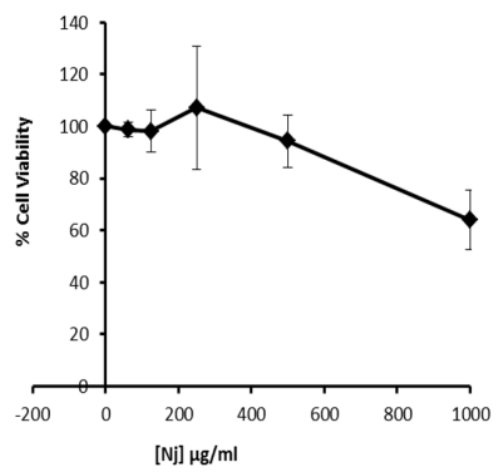

D

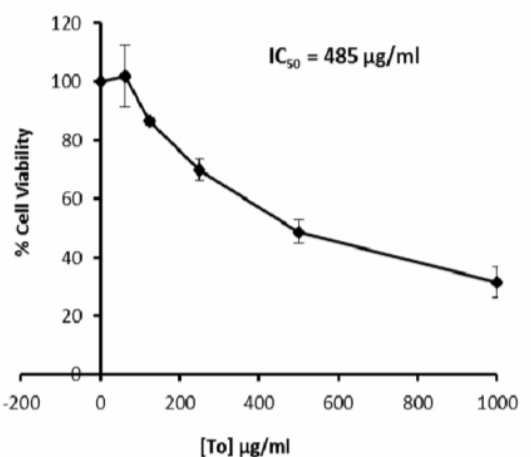

B

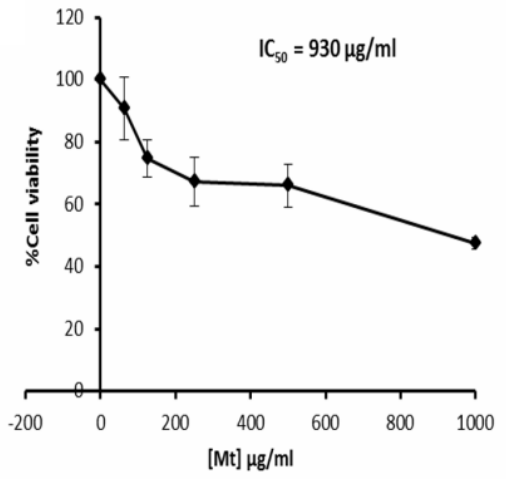

$\mathbf{E}$

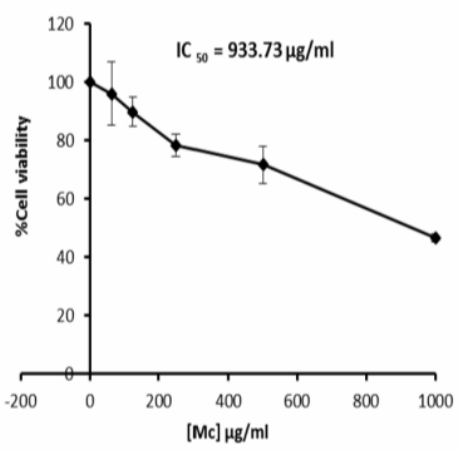

C

Figure 7. Dose-response curves showing the effects of extracts on cell viability in Jurkat leukemia cells: A. Curcumin (positive control), B. T. officinale (To), C. Morinda citrifolia (Mc), D. Noni juice (Nj), E. Millettia thonningii $(\mathrm{Mt})$; Data represent mean \pm S.D. of $n=3$.

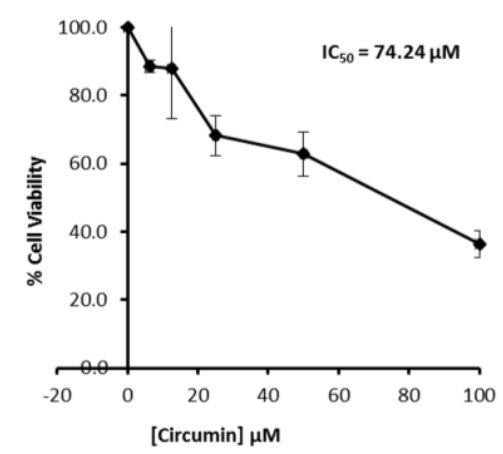

A

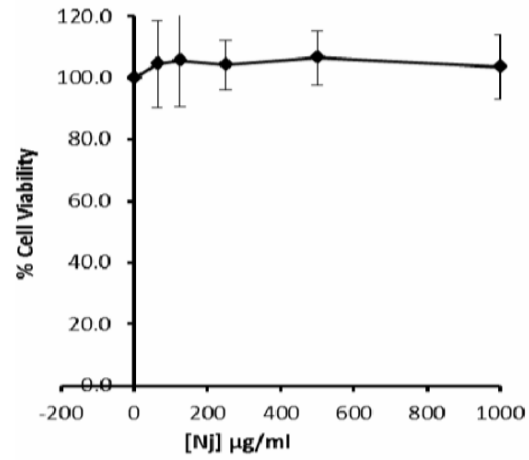

D

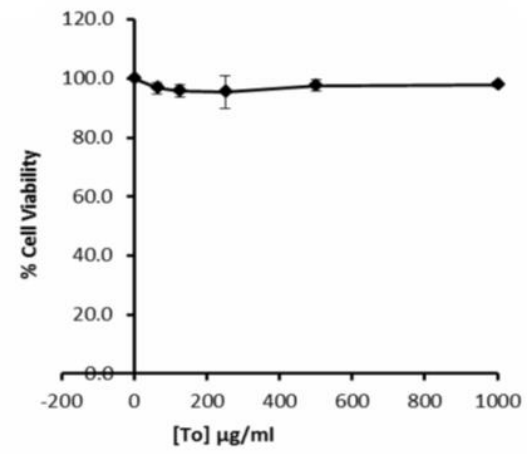

B

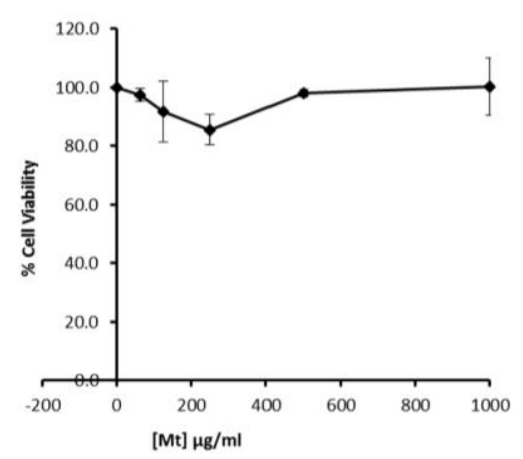

$\mathbf{E}$

Figure 8. Effects of extracts on MCF7 breast cancer cell viability: A Curcumin (positive control) B. T. officinale (To) C. M. citrifolia (Mc) D. Noni juice $(\mathrm{Nj})$ E. M. thonningii $(\mathrm{Mt})$; Data represent the mean \pm S.D. of $\mathrm{n}=3$. 
Table 2. $\mathrm{IC}_{50}$ of plant extracts and curcumin (positive control)

\begin{tabular}{|c|c|c|}
\hline \multirow[b]{2}{*}{ Extract } & \multicolumn{2}{|c|}{ I.C. 50} \\
\hline & Jurkat leukemia cells & $\begin{array}{c}\text { MCF7 breast cancer } \\
\text { cells }\end{array}$ \\
\hline Curcumin & $11.4 \mu \mathrm{M}$ & $74.74 \mu \mathrm{M}$ \\
\hline T. officinale & $485 \mu \mathrm{g} / \mathrm{mL}$ & - \\
\hline M. citrifolia & $933.33 \mu \mathrm{g} / \mathrm{mL}$ & - \\
\hline Noni juice & - & - \\
\hline M. thonningii & $930 \mu \mathrm{g} / \mathrm{mL}$ & - \\
\hline
\end{tabular}

Note: $\mathrm{IC}_{50}$; Fifty percent inhibitory concentration values of the plant extracts and the positive control (curcumin)

\section{Antioxidant activities of the selected plant extracts}

Figure 9 and Table 3 show the extracts and Noni juice's DPPH scavenging activities. Figure 9 shows the DPPH scavenging activities of the extracts and the standard over the concentration range of $0-5 \mathrm{mg} / \mathrm{mL}$. Table 3 summarizes the EC50 values. All extracts scavenged DPPH radicals in a dose-dependent manner (Fig. 9). The $\mathrm{EC}_{50}$ value for $M$. thonningii $(0.21 \mathrm{mg} / \mathrm{mL})$ was smaller compared to that of BHT $(0.43 \mathrm{mg} / \mathrm{mL})$. T. officinale also had a lower $\mathrm{EC}_{50}$ value of $0.31 \mathrm{mg} / \mathrm{mL}$ than the standard BHT. Noni juice and $M$. citrifolia had higher $\mathrm{EC}_{50}$ values of $1.98 \mathrm{mg} / \mathrm{mL}$ and $0.60 \mathrm{mg} / \mathrm{mL}$, respectively, compared to BHT. Among the extracts, $M$. thonningii had the smallest $\mathrm{EC}_{50}$ value, while Noni juice had the highest $\mathrm{EC}_{50}$ value.

\section{Phenolic content in the plant extracts}

The phenolic content of the four extracts was determined from the gallic acid calibration curve and is indicated in Table 4. M. thonningii had the highest phenolic content, followed by $M$. citrifolia and T. officinale, and Noni juice which had the lowest phenolic content.

Table 3. $\mathrm{EC}_{50}$ of plant extracts and standard (BHT)

\begin{tabular}{lc}
\hline \multicolumn{1}{r}{ Extract } & E.C. 50 \\
\hline BHT & 0.43 \\
T. officinale & 0.31 \\
M. citrifolia & 0.60 \\
Noni juice & 1.98 \\
M. thonningii & 0.21 \\
\hline
\end{tabular}

Note: EC50; Fifty percent effective concentration values of the plant extracts and the standard (BHT)

Table 4. Phenolic content of the extracts

\begin{tabular}{lc}
\hline \multicolumn{1}{c}{ Extract $(\mathbf{5} \mathbf{~ m g} / \mathbf{m L})$} & [Phenolics] $\mathbf{~ m g ~ G A E} / \mathbf{1 0 0 g}$ \\
\hline T. officinale & $7127.98 \pm 0.16$ \\
M. citrifolia & $7338.92 \pm 0.17$ \\
Noni juice & $3036.69 \pm 0.17$ \\
M. thonningii & $23880.38 \pm 0.14$ \\
\hline
\end{tabular}

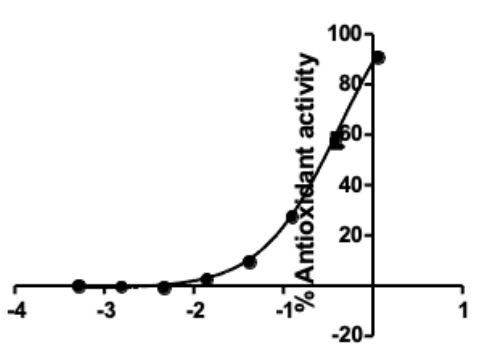

$\log [B H T] \mathrm{mg} / \mathrm{ml}$

$\mathbf{A}$

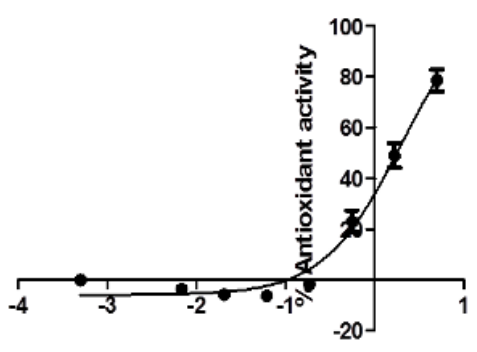

Log [Noni juice] mg/ml

D

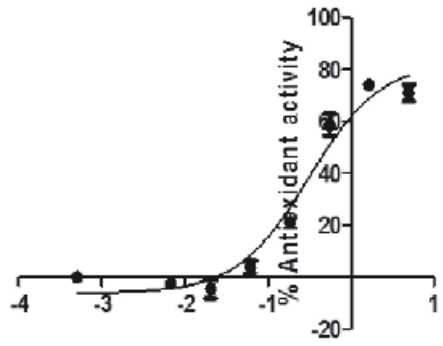

Log [T. officinale] mg/ml

B

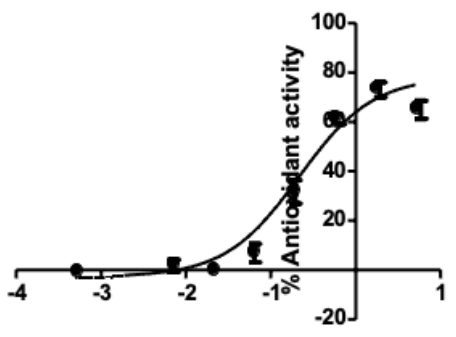

Log [M. thonningii] $\mathrm{mg} / \mathrm{ml}$

E

Figure 9. Antioxidant activities of BHT and extracts: A. Butylated hydroxyl toluene (BHT) B. T. officinale C. M. citrifolia D. Noni juice E. M. thonningii; Radical scavenging capacity of each extract calculated as the percent DPPH radical scavenging effect; Each data point is mean \pm S.D. of $n=3$ 


\section{Phytochemical constituents of the selected plant extracts}

Qualitative tests were performed to determine the extracts' alkaloids, flavonoids, cardiac glycosides, saponins, tannins, and terpenoids. Table 5 shows the results from the phytochemical analysis. All the plant extracts harbored saponins, as evidenced by the presence of emulsion. All except Noni juice tested positive for the presence of tannins. Only $M$. citrifolia and Taraxacum officinale tested positive for flavonoids, while only $M$. citrifolia tested positive for the presence of alkaloids. Terpenoids and glycosides were not found in all four extracts.

\section{Discussion}

Mitochondria are crucial and unique organelles sensitive to several xenobiotics, including drugs and phytochemicals. Some xenobiotics exhibit pharmacological effects and toxicity by interfering with mitochondrial function. Since ancient times, medicinal plants have contributed to health care and contain several phytochemicals. The present study extracts three medicinal plants to determine their phenolic content, antioxidant activities, phytochemistry as well as their effects on mitochondrial respiration and cell viability. The data indicated that all the extracts showed powerful antioxidant activities and contained phytochemical compounds known to have antioxidant properties. Nevertheless, all the extracts affected mitochondrial respiratory chain activity.

\section{Effects of the selected plant extracts on mitochondrial respiratory chain activity}

All extracts demonstrated some effect on mitochondrial respiratory chain activity. This observation agrees with previous findings that plant xenobiotics interfere with mitochondrial function (Forbes-Hernandez et al., 2014). All the tested extracts significantly stimulated basal respiration (Figures 2-5), indicating that they may contain active compounds that act as substrates and donate electrons to the enzyme complexes stabilizing their activities. Furthermore, an increase of 5-20\% in respiration was observed in the extracts with the addition of cytochrome $\mathrm{C}$. This phenomenon indicates that the outer mitochondrial membrane remained intact throughout the respiration assays (Figures 2-5).

Table 5. Qualitative screening of the phytochemicals in the extracts

\begin{tabular}{lcccc}
\hline \multirow{2}{*}{$\begin{array}{c}\text { Phyto- } \\
\text { chemicals }\end{array}$} & T. officinale & M. citrifolia & $\begin{array}{c}\text { Noni } \\
\text { juice }\end{array}$ & M. thonningii \\
\hline Alkaloids & - & + & - & - \\
Flavonoids & + & + & - & - \\
Glycosides & - & - & - & - \\
Saponins & + & + & + & + \\
Tannins & + & + & - & + \\
Terpenoids & - & - & - & - \\
\hline Nonyyy
\end{tabular}

Note: $+=$ present; $-=$ absent
Effects of the extracts on respiratory chain enzyme complexes

Taraxacum officinale seemed to have caused a decrease in complex I respiration. This phenomenon suggests that it may contain phytochemical compounds that inhibit complex I activity (Figure 2). T. officinale also seemed to have decreased the rotenone-inhibited respiration, which contradicted the previous finding (Ocloo et al. 2015), where the aqueous extract of $T$. officinale caused an increase in the rotenone-inhibited respiration and blocked the effect of rotenone. Complex II respiration was decreased in the presence of $T$. officinale extract, indicating that this extract may contain phytochemical compounds that inhibit complex II activity. Similar findings were made by Ocloo et al. (2015), where the aqueous extract of $T$. officinale caused a decrease in complex II respiration. However, consistent with previous findings (Ocloo et al. 2015), the extract of $T$. officinale causes an increase in complex IV activity and thus may contain electrondonating phytochemicals to complex IV stabilizing its activity. The discrepancy between the results obtained in this study and obtained by Ocloo et al. (2015) may be due to varied chemical constituents in the $T$. officinale extracts due to differences in plant location, time of harvesting, and preparation method.

Morinda citrifolia appears to have decreased complex I respiration, suggesting that it may contain phytochemical compounds that inhibit complex I activity (Figure 3). $M$. citrifolia also appears to have decreased complex II respiration, suggesting that it may contain active compounds that inhibit complex II activity. However, $M$. citrifolia was the only extract that significantly increased complex IV respiration. This suggests that $M$. citrifolia might contain phytochemical compounds that donate electrons to complex IV and stimulate its activity.

Noni juice appears to have decreased complex I respiration, suggesting that it may contain phytochemical compounds that inhibit complex I activity (Figure 4). However, it does not appear to alter complex II respiration. Noni juice was the only extract that caused an increase in antimycin A-inhibited respiration. This suggests that the juice may contain compounds that donate electrons downstream of complex III to complex IV and block the effect of antimycin A. Respiration of complex IV is also increased in the presence of Noni juice, suggesting that Noni juice extracts may contain phytochemical compounds that stimulate complex IV activity by donating electrons to complex IV.

Figure 5 shows that $M$. thonningii did not affect complex I respiration. This result contradicts the previous study, which showed $M$. thonningii seeds inhibited complex I respiration (Lyddiard and Whitfield 2001). Among other extracts, $M$. thonningii was the only extract that caused an increase in the rotenone-inhibited respiration, suggesting that it may contain phytochemicals that donate electrons downstream of complex I, II, III, and IV and block the effect of rotenone.

Millettia thonningii appears to have decreased complex II respiration, suggesting that it may contain phytochemical compounds that inhibit complex II activity. M. thonningii leaves are known to have molluscicidal activity (Harrison 
et al., 2011). Inhibition of complex II activity by $M$. thonningii extract may partly explain the mechanism involved in leaf mollusk activity. In addition, $M$. thonningii stimulated complex IV activity, suggesting that $M$. thonningii may contain phytochemical compounds that deliver electrons to complex IV and stabilize its activity.

\section{Effects of the extracts on ATP synthesis}

ADP-stimulated respiration was increased only in the presence of $M$. thonningii extract, suggesting that this extract may contain phytochemicals that stimulate the synthesis of ATP (Figure 5). However, the other extracts appeared to have decreased ADP-stimulated respiration, indicating that they may contain compounds that inhibit ATP synthesis (Figures 2-4). Previously, the aqueous extract of $T$. officinale did not affect ADP-stimulated respiration (Ocloo et al., 2015).

\section{Effects of the extracts on respiratory control ratio ( $R C R)$}

The respiratory control ratio can be defined as the ratio of state three respiration to state two respiration. It is a way of measuring coupling efficiency. All the extracts appeared to have increased coupling (Table 1). On the other hand, Noni juice appeared to have decreased coupling compared to the solvent, casting doubt on its effectiveness as an energy booster. Similar to these results, a previous study showed that the aqueous extract of $T$. officinale also increased coupling (Ocloo et al., 2015).

\section{Effects of the extracts on leak respiration}

Oxidative phosphorylation is not perfectly coupled because protons can leak across the inner membrane. Leaked respiration is an indirect measure of the leakage of protons across the inner membrane. It is also an indirect estimate of the coupling efficiency. It is measured as mitochondrial respiration in the absence of ADP but in the presence of reducing substrates (Gnaiger 2012). High leakage respiration indicates high uncoupling. None of the extracts significantly altered respiratory leakage compared to the solvent (Figure 6), indicating low proton leakage across the inner mitochondrial membrane.

\section{Cytotoxicity of the selected plant extracts}

The cytotoxicity of the selected plant extracts was measured by the effects of the extracts on mitochondrial function using the MTT assay. The principle of MTT assay is based on the enzymatic reaction in the mitochondria that converts MTT to formazan in viable cells (Slater et al. 1963). The extracts appeared to show dose-dependent cytotoxic effects on the Jurkat leukemia cells (Figure 8). However, according to the U.S. National Cancer Institute, a plant extract is considered to have an active cytotoxic effect if the $\mathrm{IC}_{50}$ value is $30 \mu \mathrm{g} / \mathrm{mL}$ or less (Geran et al. 1972; Lee and Houghton 2005). All the extracts demonstrated IC50 values greater than $100 \mu \mathrm{g} / \mathrm{mL}$ in the present study. Based on the MTT result, the extracts had weak cytotoxic effects on the Jurkat leukemia cells. Thus, they lack the potential to alter mitochondrial function significantly. The extracts also appeared to have had no cytotoxic effect on the MCF7 breast cancer cells (Figure 8), suggesting that mitochondrial function might be unaffected by the extracts.

Anecdotal information on the anticancer activity of $T$. officinale has been reported previously (Sigstedt et al. 2008). The aqueous leaf extract of $T$. officinale has been shown to reduce the growth of MCF-7/AZ breast cancer cells in a dose-dependent manner (Sigstedt et al. 2008). This inhibitory effect is ascribed to the presence of phenolic compounds in the Dandelion leaves (Schütz et al., 2006). However, T. officinale showed weak cytotoxic effects on the cell lines used in this study. It is also possible that $T$. officinale acts as a pro-drug; thus, in vitro assays alone may be inappropriate for investigating its anticancer property.

There are also reports of the anticancer properties of Noni juice. Fruit juices have been reported to have significant antitumor activity against peritoneal carcinomatosis LLC (Hirazumi et al. 1996). In addition, the methanol extract of the fruit showed cytotoxic activity against breast cancer (MCF7) and neuroblastoma cell lines (LAN5) (Arpornsuwan and Punjanon 2006). Another study showed that polysaccharide-rich substances precipitated ethanol from Noni juice had immunomodulatory and antitumor activity against ascitic tumors Sarcoma 180 in mice (Furusawa et al. 2003). However, Noni juice had a weak cytotoxic effect against the cancer cell lines based on this study. This result does not agree with the observations in the earlier studies. The difference in cytotoxic effect is probably due to the juice preparation methods since the practice is quite elaborate. Noni juice is fermented for two months, during which light intensity, $\mathrm{pH}$, and temperature are carefully monitored. This may or may not be followed by pasteurization. Furthermore, this study did not investigate methanolic extracts of the fruit reported to possess cytotoxic activity.

Although there have been reports of anticancer activity of extracts of $T$. officinale and Noni juice, the findings obtained in this study do not support these claims. The weak cytotoxic effects of the extracts on the cell lines are unclear due to the lack of information on the anticancer properties of the $M$. citrifolia and $M$. thonningii leaves.

\section{Antioxidant activities and phenolic contents of the selected plant extracts}

Free radicals such as reactive oxygen species (ROS) are typical by-products of respiration. However, an overload of free radicals may lead to oxidative damage. Imbalances of cellular redox homeostasis contribute to the pathogenesis of diseases such as diabetes, atherosclerosis, immunosuppression, and neurodegeneration (Hensley et al., 2000; Gupta et al., 2012). Antioxidants are chemical compounds that include nutrients, vitamins, and minerals, scavenging free radicals and protecting cellular DNA, proteins, and lipid membranes (Osawa et al. 1990). In addition, antioxidants have been implicated in maintaining human health and preventing and treating several diseases (Halliwell and Gutteridge 1981).

Of the plant extracts analyzed, $M$. thonningii showed the strongest antioxidant activity (Table 3). On the other hand, noni juice showed the lowest antioxidant activity 
among the four extracts. However, Noni juice is considered a good source of antioxidants and polyphenols (Bramorski et al., 2010; De-Lu et al., 2013). M. citrifolia leaves are well known for their strong antioxidant activity and are safe in acute, subacute, and subchronic oral toxicity tests in rats (West et al., 2007; Serafini et al., 2011). The results obtained in this study confirm the potent antioxidant activity of the $M$. citrifolia leaves. $T$. officinale is an easily accessible source of natural antioxidants (Amin et al., 2013). In a previous study, T. officinale effectively scavenged free radicals released in the liver in rats with CCl4-induced hepatotoxicity (Gulfraz et al. 2014). Dandelion also reduced atherosclerosis by reducing oxidative stress in cholesterol-fed rats (Choi et al. 2010). The results obtained in this study agree with previous findings and confirm the antioxidant properties of $T$. officinale.

Phenols have been shown to have antioxidant activity against free radicals. The antioxidant action of phenolic compounds is due to their high tendency to chelate metals. Phenolics have hydroxyl and carboxyl groups, able to bind mainly iron and copper (Jung et al. 2003). Therefore, measuring the concentration of phenolic hydroxyl groups in plant extracts is another way to confirm antioxidant capacity. In addition, a high linear correlation has been observed between the radical scavenging activity of DPPH and the total phenolic content (Ghafar et al., 2010). Li et al. (2009) also identified a significant positive correlation between antioxidant effects and the presence of phenolic compounds in Radix angelica sinensis. The results obtained in this study are in accordance with previous findings. Intriguingly, $M$. thonningii, which showed the most potent antioxidant activity, had the highest phenolic content. On the contrary, Noni juice which showed the weakest antioxidant activity had the lowest phenolic content in the present study (Table 3 ).

\section{Phytochemical constituents of the selected plant extracts}

Studies on medicinal plants have indicated phytochemicals such as phenolics, flavonoids, and tannins (Hill 1952). These phytochemicals often determine the physiological action of medicinal plants on the human body and have beneficial effects on health (Pamplona-Roger, 1998; Ayoola et al., 2008). Some phytochemicals are antioxidants and thus attenuate the deleterious effects of reactive oxygen species. The plant extracts were screened for six classes of phytochemicals commonly found in most plants in the current study. These phytochemicals include alkaloids, flavonoids, saponins, glycosides, tannins, and terpenoids. The result showed that each extract contained at least one of these phytochemicals.

The aqueous extract of Millettia thoninngii leaves contained saponins and tannins (Table 5). Saponins and tannins are phytochemicals known to have antioxidant properties (Chen et al., 2014; Forbes-Hernández et al., 2014). Both phytochemicals, as well as glycosides, alkaloids, flavonoids, and terpenoids, are in the leaves of M. Thonningii (Borokini and Omotayo (2012). In another study, isoflavonoids were placed in the deuterochloroform extract of hexane-defatted seeds of $M$. thonningii (Lyddiard and Whitfield 2001).

Saponins, flavonoids, and tannins were identified in the aqueous extract of $T$. officinale leaves (Table 5). These phytochemicals are well-known plant components (Yarnell and Abascal 2009). Flavonoids are polyphenols with antioxidant properties (Pietta 2000; Forbes-Hernández et al. 2014). In the earlier studies, T. officinale leaves were rich in phenolics and other antioxidants such as vitamin A, vitamin C, zinc, and copper (Schmidt 1979; Jackson 1982; Yarnell and Abascal 2009).

Morinda citrifolia leaves contain alkaloids, flavonoids, saponins, and tannins (Table 5). These secondary metabolites have been identified in previous studies on the M. citrifolia plant (Singh et al., 2012; Pandy et al., 2014). Other constituents identified in the $M$. citrifolia products include vitamin A, vitamin $\mathrm{C}$, rutin, and flavone glycosides (Higa and Fuyama 1993; Farine et al. 1996). Several alkaloids have been shown to have antioxidant properties (Maiza-Benabdesselam et al., 2007). Noni juice is a rich source of antioxidants such as flavonoids (Nijveldt et al. 2001). Studies on the chemical composition of noni juice also show that the dominant phenolic compounds in noni juice function as free radical scavengers and prevent several diseases (Dixon et al. 1999; Chan-Blanco et al. 2006). Contrary to these findings, only saponins were identified in the juice.

The extract contains various classes of phytochemicals and has been shown to affect mitochondrial function. However, the phytochemical analysis carried out in this study was only limited to qualitative analysis because the quantitative analysis was not carried out. Therefore, the relationship between the phytochemicals of the extract and the observed effects on mitochondrial function is unclear. M. thonningii, for example, had the highest antioxidant activity and the highest phenolic content, including saponins and tannins. Saponins and tannins have antioxidant properties. Therefore, it is not surprising that M. thonningii extract appears to have stimulated complex IV activity and removed inhibition of complex I by rotenone. However, because the concentrations of the saponins and tannins in the extract were not determined, it is difficult to tell if these effects result from these phytochemicals alone or a combination of other factors.

Comparing the four extracts showed a similar effect on complex IV by stimulating complex IV activity. They also increase basal respiration in the absence of a substrate. However, the extract results in complexes I, II, and III differed. Each extract contains saponins. T. officinale, $M$. citrifolia, and $M$. thonningii also contain tannins. $T$. officinale and $M$. citrifolia contained flavonoids and saponins, and tannins and alkaloids were also detected in $M$. citrifolia. The amount of each phytochemical that contributes to the observed antioxidant effects of the mitochondrial complex was not determined in this study. The varied impact on complexes I, II, and III may be attributed to different concentrations of the phytochemicals in each extract. For example, although four phytochemicals were identified in $M$. citrifolia and only two were identified in M. thonningii, the latter had a higher antioxidant activity, 
probably due to higher concentrations of the phytochemicals identified in this extract. No clear association was observed between the phytochemicals identified in each extract and their observed effects on mitochondrial function.

A positive linear relationship between antioxidant activity and the anticancer effect of the aqueous extracts of five herbal plants (L. chinensis, R. officinale, S. officinalis, A. Pilosa, and P. polyphylla) was identified by comparing the percentage free radical scavenging capacity and percentage growth inhibition on MCF-7 and A549 cells ( $\mathrm{Li}$ et al. 2007). This result suggested that the antioxidants present in the herbal water extracts might have contributed to their anticancer effects on both cell lines. However, no relationship between antioxidant and anticancer activity was observed in this study. Although the extract exhibited prominent antioxidant activity, its growth inhibitory effect on Jurkat leukemia cells and MCF-7 cells was generally weak.

In conclusion, all the extracts significantly stimulated basal respiration, and they all appeared to increase complex IV respiration, albeit only Morinda citrifolia produced a significant increase. All the extracts showed vigorous antioxidant activities, and all of them contained phytochemicals exhibiting antioxidant properties. $M$. thonningii partially blocks the effects of rotenone. Noni juice partially blocks the effects of antimycin A. Finally, all the extracts demonstrated weak cytotoxic effects on Jurkat human leukemia and the MCF7 human breast cancer cell lines.

\section{REFERENCES}

Amin MM, Sawhney SS, Jassal MS. 2013. Comparative antioxidan power determination of Taraxacum officinale by frap and DTPH method. Pharm Anal Acta 4 (3): 1-5.

Arpornsuwan T, Punjanon T. 2006. Tumor cell-selective antiproliferative effect of the extract from Morinda citrifolia fruits. Phytother Res 20 (6): 515-517. DOI: $10.1002 /$ ptr.1902

Ayisi NK, Appiah-Opong R, Gyan B, BugyeiK, Ekuban F. 2011. Plasmodium falciparum: Assessment of selectivity of action of Chloroquine, Alchornea cordifolia, Ficus polita, and other drugs by a Tetrazolium-Based Colorimetric Assay. Malar Res Treat: 1-7. DOI: $10.4061 / 2011 / 816250$

Ayoola GA, Folawewo AD, Adesegun SA, Abioro OO, Adepoju-Bello AA, Coker HA. 2008. Phytochemical and antioxidant screening of some plants of Apocynaceae from South West Nigeria. Afr J Plant Sci 2 (10): 124-128.

Blois MS. 1958. Antioxidant determinations by the use of a stable free radical. Nature 181: 1199-1200. DOI: 10.1038/1811199a0

Borokini TI, Omotayo FO. 2012. Phytochemical and ethnobotanical study of some selected medicinal plants from Nigeria. J Med Plants Res 6 (7): 1106-1118. DOI: 10.5897/JMPR09.430

Bramorski A, da Rosa Cherem A, Marmentini CP, Torresani J, Mezadri T, de Almeida Silva Costa A. 2010. Total polyphenol content and antioxidant activity of commercial Noni (Morinda citrifolia L.) juice and its components. Braz J Pharm Sci 46 (4): 651-656. DOI: 10.1590/S1984-82502010000400006

Chan-Blanco Y, Vaillant F, Perez AM, Reynes M, Brillouet JM, Brat P. 2006. The Noni fruit (Morinda citrifolia L.): A review of agricultural research, nutritional and therapeutic properties. J Food Compos Anal 19: 645-654. DOI: 10.1016/j.jfca.2005.10.001

Chen Y, Miao Y, Huang L, Li J, Sun H, Zhao Y, Yang J, Zhou W. 2014 Antioxidant activities of saponins extracted from Radix trichosanthis: An in vivo and in vitro evaluation. BMC Complement Altern Med 14 (86): 1-8. DOI: $10.1186 / 1472-6882-14-86$
Choi U, Lee O, Yim JH, Cho C, Rhee YK, Lim S, Kim Y. 2010 Hypolipidemic and antioxidant effects of Dandelion (Taraxacum officinale) root and leaf on cholesterol-fed rabbits. Int J Mol Sci 11: 67-78. DOI: 10.3390/ijms11010067

Deavall DG, Martin EA, Horner JM, Roberts R. 2012. Drug-induced oxidative stress and toxicity. J Toxicol 201: 1-13. DOI: $10.1155 / 2012 / 645460$

De-Lu M, Chen M, Su CX, West BJ. 2013. In vivo antioxidant activity of deacetylasperulosidic acid in Noni. J Anal Methods Chem 1-5. DOI: 10.1155/2013/804504

Dixon AR, Mcmillen H, Etkin NL. 1999. Ferment this: the transformation of Noni, a traditional Polynesian medicine (Morinda citrifolia, Rubiaceae). Ecol Bot 53: 51-68. DOI: 10.1007/BF02860792

Evans WC. 2002. Trease \& Evans Pharmacognosy. 15th Edn. Saunders, USA.

Farine JP, Legal L, Moreteau B, Le Quere JL. 1996. Volatile components of ripe fruits of Morinda citrifolia and their effects on Drosophila. Phytochemistry 41: 433-438. DOI: 10.1016/0031-9422(95)00455-6

Forbes-Hernández TY, Giampieri F, Gasparrini M, Mazzoni L, Quiles JL, Alvarez-suarez JM, Battino M. 2014. The effects of bioactive compounds from plant foods on mitochondrial function: A focus on apoptotic mechanisms. Food Chem Toxicol 68: 154-182. DOI: 10.1016/j.fct.2014.03.017

Furusawa E, Hirazumi A, Story S, Jensen J. 2003. Antitumour potential of a polysaccharide-rich substance from the fruit juice of Morinda citrifolia (Noni) on sarcoma 180 ascites tumour in mice. Phytother Res 17 (10): 1158-1164. DOI: 10.1002/ptr.1307

Geran RI, Greenberg NH, McDonald MM, Schumacher AM, Abbott BJ. 1972. Protocols for screening chemical agents and natural products against animal tumour and other biological systems. Cancer Chemother Rep 3: 17-19.

Ghafar MFA, Prasad KN, Weng KK, Ismail A. 2010. Flavonoid, hesperidine, total phenolic contents and antioxidant activities from Citrus species. Afr J Biotechnol 9 (3): 326-330.

Gnaiger E. 2012. Mitochondrial pathways and respiratory control: An introduction to OXPHOS analysis. Axams, Innsbruck, Steiger Druck $\mathrm{GmbH}$, Austria.

Gohil VM, Sheth SA, Nilsson R, Wojtovich AP, Lee JH, Perocchi F, Chen W, Clish CB, Ayata C, Brookes PS, Mootha VK. 2010. Nutrient-sensitized screening for drugs that shift energy metabolism from mitochondrial respiration to glycolysis. Nat Biotechnol 28: 249255. DOI: $10.1038 /$ nbt.1606

Gulfraz M, Ahamd D, Ahmad MS, Qureshi R, Mahmood RT, Jabeen N, Abbasi KS. 2014. Effect of leaf extracts of Taraxacum officinale on CCl4 induced hepatotoxicity in rats, in vivo study. Pak J Pharm Sci 27 (4): 825-829

Gupta SC, Hevia D, Patchva S, Park B, Koh W, Aggarwal BB. 2012. Upsides and downsides of reactive oxygen species for cancer: the roles of reactive oxygen species in tumorigenesis, prevention, and therapy. Antioxid Redox Signal 16 (11): 1295-1322. DOI: 10.1089/ars.2011.4414

Halliwell B, Gutteridge JMC. 1981. Formation of thiobarbituric acid reactive substances from deoxyribose in the presence of iron salts: the role of superoxide and hydroxyl radicals. FEBS Lett 128: 347-352. DOI: 10.1016/0014-5793(81)80114-7

Harrison JJEK, Dankyi E, Kingsford-Adaboh R, Ishida H. 2011. In search of new leads: a closer look at the therapeutic potential of the constituents of Millettia thonningii, Millettia pachycarpa and their structural analogues. Int J Pharm Pharm Sci 3 (2): 71-81.

Hensley K, Robinson KA, Gabbita SP, Salsman S, Floyd RA. 2000. Reactive oxygen species, cell signaling, and cell injury. Free Radic Biol Med 28 (10): 1456-1462. DOI: 10.1016/S0891-5849(00)00252-5

Higa I, Fuyama Y. 1993. Genetics of food preference in Drosophila sechellia. I. Responses to food attractants. Genetica 88 (2-3): 129136. DOI: $10.1007 / \mathrm{BF} 02424469$

Hill AF. 1952. Economic Botany. A textbook of useful plants and plant products. $2^{\text {nd }}$ edn. McGarw-Hill Book Company Inc., New York. DOI: 10.1002/j.1537-2197.1952.tb13083.x

Hirazumi A, Furusawa E, Chou SC, Hokama Y. 1996. Immunomodulation contributes to the anticancer activity of Morinda citrifolia (Noni) fruit juice. Proc West Pharmacol Soc 39: 7-9.

Huang S, Bi K, Kuo H, Linc T, Liao P, Wang P, Chuang J, Liouc C. 2014. Phyllanthus urinaria induces mitochondrial dysfunction in human osteosarcoma 143B cells associated with modulation of mitochondrial fission/fusion proteins. Mitochondrion 17: 22-33. DOI: 10.1016/j.mito.2014.05.002 
Jackson BS. 1982. The lowly dandelion deserves more respect. Can Geogr 102: 54-59.

Jadhav AP, Kareparamban JA, Nikam PH, Kadam VJ. 2012. Spectrophotometric estimation of ferulic acid from Ferula asafoetida by Folin-Ciocalteu's Reagent. Der Pharmacia Sin 3 (6): 680-684.

Jung CH, Maeder V, Funk F, Frey B, Sticher H, Frosserd E. 2003. Release of phenols from Lupinus albus $\mathrm{L}$. roots exposed to $\mathrm{Cu}$ and their possible role in $\mathrm{Cu}$ detoxification. Plant Soil 252: 301-312. DOI: 10.1023/A:1024775803759

Kuznetsov AV, Veksler V, Gellerich FN, Saks V, Margreiter R, Kunz WS. 2008. Analysis of mitochondrial function in situ in permeabilized muscle fibers, tissues, and cells. Nat Protoc 3 (6) 965 976. DOI: $10.1038 /$ nprot.2008.61

Lee CC, Houghton P. 2005. Cytotoxicity of plants from Malaysia and Thailand used traditionally to treat cancer. J Ethnopharmacol 100 237-243. DOI: 10.1016/j.jep.2005.01.064

Lewis W, Dalakas MC. 1995. Mitochondrial toxicity of antiviral drugs. Nat Med 1: 417-422. DOI: 10.1038/nm0595-417

Lewis W, Day BJ, Copeland WC. 2003. Mitochondrial toxicity of NRTI antiviral drugs: An integrated cellular perspective. Nat Rev Drug Discov 2: 812-822. DOI: 10.1038/nrd1201

Li W, Chan S, Guo D, Yu PH. 2007. Correlation between antioxidative power and anticancer activity in herbs from traditional Chinese medicine formulae with anticancer therapeutic effect. Pharm Biol 45 (7): 541-546. DOI: 10.1080/13880200701498879

Li X, Wu X, Huang L. 2009. Correlation between antioxidant activities and phenolic contents of Radix angelicae sinensis (Danggui) Molecules 14: 5349-5361. DOI: 10.3390/molecules14125349

Lyddiard JRA, Whitfield PJ. 2001. Inhibition of site I mitochondrial electron transport by an extract of the seeds of Millettia Thonningii: a potential mechanism for the plant's molluscicidal and schistosome larvicidal activity. J Helminthol 75: 259-265.

Maiza-Benabdesselam F, Khentache S, Bougoffa K, Chibane M, Adach S, Chapeleur Y, Max H, Laurain-Mattar D. 2007. Antioxidant activities of alkaloid extracts of two Algerian species of Fuíia : Fumaria capreolata and Fumaria bastardii. Rec Nat Prod 1 (2-3): 28-35.

Marinova D, Ribarova F, Atanassova M. 2005. Total phenolics and total flavonoids in Bulgaria fruits and vegetables. J Univ Chem Technol Metallurgy 40: 255-260.

Mir MA, Sawhney SS, Jassal MMS. 2013. Qualitative and quantitative analysis of phytochemicals of Taraxacum officinale. Wudpecker $\mathbf{J}$ Pharm Pharmocol 2 (1): 001-005.

Nadanaciva S, Bernal A, Aggeler R, Capaldi R, Will Y. 2007. Target identification of drug induced mitochondrial toxicity using immunocapture based OXPHOS activity assays. Toxicol In Vitro 110. DOI: $10.1016 /$ j.tiv.2007.01.011

Nijveldt RJ, Nood E, Hoorn DE, Boelens PG, Norren K, Leeuwen PAM 2001. Flavonoids: a review of probable mechanisms of action and potential applications. Am Soc Clin Nutr 74: 418-425. DOI 10.1093/ajcn/74.4.418

Ocloo A, Appiah-Opong R, Chama MA, Appiah AA, Murray AJ. 2015. An in situ study on the effects of extracts of Taraxacum officinale, Paulliniia pinnata and Thonningia sanguinea on mitochondrial function. J Food Biochem 1-7.

Osawa T, Kavakishi S, Namiki M, Kuroda Y, Shankal DM, Waters MD. 1990. Antimutagenesis and anticarcinogenesis mechanisms II. Plenum, New York. DOI: 10.1007/978-1-4615-9561-8_11
Pamplona-Roger D. 1998. Encyclopedia of Medicinal Plants. Editorial Saeliz, Spain.

Pandy V, Narasingam M, Kunasegaran T, Murugan DD, Mohamed Z. 2014. Effect of Noni (Morinda citrifolia Linn.) fruit and its bioactive principles scopoletin and rutin on rat vas deferens contractility: An ex vivo study. Sci World J 1-11. DOI: 10.1155/2014/909586

Pietta P. 2000. Flavonoids as antioxidants. J Nat Prod 63: 1035-1042. DOI: $10.1021 / \mathrm{np} 9904509$

Scatena R, Bottoni P, Botta G, Martorana GE. 2007. The role of mitochondria in pharmacotoxicology: A re-evaluation of an old, newly emerging topic. Am J Physiol Cell Physiol 1-44. DOI: 10.1152/ajpcell.00314.2006

Schmidt M. 1979. The delightful dandelion. Organic Gard 26: 112-117.

Schofield P, Mbugua DM, Pell AN. 2001. Analysis of condensed tannins: A review. Anim Feed Sci Technol 91: 21-40. DOI: 10.1016/S03778401(01)00228-0

Schütz K, Carle R, Schieber A. 2006. Taraxacum-a review on its phytochemical and pharmacological profile. J Ethnopharmacol 107 (3): 313-323. DOI: 10.1016/j.jep.2006.07.021

Serafini F, Bottacini F, Viappiani A, Baruffini E, Turroni F, Foroni E, Lodi T, van Sinderen D, Ventura M. 2011. Insights into physiological and genetic mupirocin susceptibility in bifidobacteria. Appl Environ Microbiol 77: 3141-3146. DOI: 10.1128/AEM.02540-10

Sigstedt SC, Hooten CJ, Callewaert MC, Jenkins AR, Romero AE, Pullin MJ, Kornienko A, Lowrey TK, Slambrouck SV, Steelant WF. 2008. Evaluation of aqueous extracts of Taraxacum officinale on growth and invasion of breast and prostate cancer cells. Int J Oncol 32 (5): 1085-1090. DOI: /10.3892/ijo.32.5.1085

Silva MFB, Aires CCP, Luis PBM, Ruiter JPN, Jlst LI, Duran M, Wanders RJA, Tavares de Almeida I. 2008. Valproic acid metabolism and its effects on mitochondrial fatty acid oxidation: A review. J Inherit Metab Dis 31: 205-216. DOI: 10.1007/s10545-008-0841-x

Singh D, Singh P, Gupta A, Solanki S, Sharma E, Nema R. 2012. Qualitative estimation of the presence of bioactive compound in Centella asiatica: An important medicinal plant. Int J Life Sci Med Sci 2 (1): 5-7. DOI: 10.5963/LSMR0201002

Slater TF, Swyer B, Straeuli U. 1963. Studies on succinate-tetrazolium reductase systems. III. Point of coupling of four different tetrazolium salts. Biochim Biophys Acta 77: 383-393. DOI: 10.1016/00063002(63)90513-4

Smith RAJ, Hartley RC, Cocheme HM, Murphy MP. 2012. Mitochondrial pharmacology. Trends Pharmacol Sci 33 (6): 341-352. DOI: /10.1016/j.tips.2012.03.010

Sofowora A. 1993. Medicinal plants and traditional medicine in Africa. Spectrum Books Ltd., Ibadan.

Strathkelvin Instruments Ltd. 2012. Instruction Manual: 782 Oxygen Meter. Rowantree Avenue. Strathkelvin Instruments Ltd., Scotland.

Wallace DC. 2013. A mitochondrial bioenergetic etiology of disease. J Clin Invest 123 (4): 1405-1412. DOI: 10.1172/JCI61398

Wallace KB, Starkov AA. 2000. Mitochondrial targets of drug toxicity. Annu Rev Pharmacol Toxicol 40: 353-88. DOI: 10.1146/annurev.pharmtox.40.1.353

West BJ, Tani H, Palu AK, Tolson CB, Jensen CJ. 2007. Safety tests and antinutrient analyses of Noni (Morinda citrifolia L.) leaf. J Sci Food Agric 87: 2583-2588. DOI: 10.1002/jsfa.3007

Yarnell E, Abascal K. 2009. Dandelion (Taraxacum officinale and $T$ mongolicum). Integr Med 8 (2): 35-38. 